\title{
Internal Structure and Consistency of the Spanish Version of the Six-Item Female Sexual Function Index
}

\author{
Monterrosa-Castro $\mathrm{A}^{1 *}$, Campo-Arias $\mathrm{A}^{\mathbf{2}}$ and Herazo $\mathrm{E}^{3}$ \\ ${ }^{1}$ MD. Professor. Grupo de Investigación Salud de la Mujer. Facultad de Medicina. Universidad de Cartagena. Cartagena. Colombia \\ ${ }^{2}$ MD. MSc. Profesor. Escuela de Medicina. Facultad de Ciencias de la Salud. Universidad del Magdalena. Santa Marta. Colombia \\ ${ }^{3}$ MD. MSc, PhD (C). Human Behavioral Research Institute. Bogota. Colombia
}

*Corresponding author: Alvaro Monterrosa-Castro. La Matuna. Avenida Venezuela. Edificio City Bank Of. 6-a. Tel: +573157311275. Cartagena.

Colombia. Email: alvaromonterrosa@gmail.com

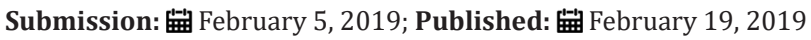

\begin{abstract}
Objective: The purpose of this paper is to evaluate the structure of the Spanish version of the FSFI-6 in climacteric Colombian women.

Methods: The validation study involved 1,427 sexually active women aged between 40 and 59 years. Cronbach's alpha, McDonald's omega and confirmatory factor analysis were calculated.
\end{abstract}

Results: The Cronbach's alpha was 0.876 and the McDonald's omega was 0.886 . The one- dimension model did not fit, chi-square $=582.04, \mathrm{df}=9$, $\mathrm{p}<0.001, \mathrm{RMSEA}=0.211(90 \% \mathrm{CI} 0.197-0.226), \mathrm{CFI}=0.888$ and $\mathrm{TLI}=0.813$.

Conclusion: The FSFI-6 presents a one-dimensional structure with high internal consistency in climacteric women from the Caribbean coast of Colombia. But, the data's goodness of fit is inadequate. These findings need to be verified in other populations.

Keywords: Physiological sexual dysfunction; climacteric; Reliability and validity; Validation studies

\section{Introduction}

Sexual dysfunctions are a mixed group of clinical syndromes, typically characterized by a clinically important impairment in a person's ability to experience sexual pleasure or respond sexually. Female sexual dysfunction, as defined by the latest version of the Diagnostic and Statistical Manual of Mental Disorder (DSM-5), has been separated into several categories, including orgasmic disorder, sexual interest/arousal disorder, Genito-pelvic pain/penetration disorder, substance/medication induced sexual dysfunction, other specified sexual dysfunction, and unspecified sexual dysfunction [1]. Female sexual dysfunction is highly prevalent, but, according to the background and measurement instrument, this prevalence is variable around the world [2,3]. Several factors including physiological, anatomical, and socio-cultural aspects are related to female sexual dysfunction $[4,5]$, the most prevalent of which is hypoactive desire disorder [2]. In Latin America, female sexual dysfunction is close to $20 \%$ in Colombia and reaches $98 \%$ in Ecuador [6-8].

The psychometric performance of scales varies according to the population's characteristics. However, a similar functioning in different population groups is an important empirical approximation to the validity and reliability of a measurement [9]. Factor analysis is frequently used to test the dimensionality of health measurement instruments and thereby to indirectly demonstrate the construct validity [10]. Rosen et al. [11] introduced the Female Sexual Function Index (FSFI-19) to evaluate the sexual response over the previous four weeks. Subsequently, a short version (FSFI-6) was designed by Isidori et al. [12], who observed acceptable internal consistency (Cronbach's alpha=0.79) and stability (Pearson correlation $=0.95$ ) in a sample of 184 women aged between 21 and 41 . However, the dimensionality of the FSFI6 was omitted. Subsequently, other investigations replicated the high values of internal consistency and the convergent, divergent, discriminant and nomological validity of the instrument [13-16].

Finally, using a sample of 307 women from the general population and another of 68 from the clinical practice, aged between and 21 and 66, the one-dimensional structure of the Portuguese version of the FSFI- 6 was tested using confirmatory factor analyses. Several translations of both FSFI-6 and FSFI-19 are now available, not all of them have been adequately analyzed and there is little information regarding the ability of those versions to reproduce the dimensionality and then the construct $[17,18]$. Although, a Spanish version of the FSFI-6 has been applied to assess sexual problems, its dimensionality and construct validity are still unknown $[13,14]$. The purpose of this study was to evaluate the 
dimensionality and internal consistency of a Spanish version of the FSFI- 6 in a large sample of Colombian Caribbean women, to deepen the psychometric performance of the index given the need to corroborate the validity and reliability of a health measurement instrument in different contexts. In addition, the McDonald omega was calculated as a complementary measure of internal consistency reliability.

\section{Methods}

A psychometric or validation study was designed, and approval was obtained from the research ethics board. Participants gave their informed consent. The information was collected after a pilot test applied to a group of twenty women. Questionnaires from this group of women are not included in the present analysis. The scales were applied at home. A trained health professional applied the FSFI-6.

\section{Subjects}

The study involved 1427 climacteric sexually active women from several Caribbean coastal cities in Colombia (Barranquilla, Cartagena and Monteria). The participants were aged between 40 and 59 years (mean=47,7; SD=5,6). Formal education in years was between zero and 20 (mean=9,7; SD=4,0). In terms of occupation, 784 were housewives (54,9\%); 621 employees (43,5\%); and 22 were retired $(1,6 \%)$. In terms of ethnic origin: 882 were mestizo (61,8\%), 388 Afro-Colombian (27,2\%), and 157 Amerindian $(11,0 \%)$.

\section{Instrument}

Women completed the six items of the Spanish version of the FSFI-6. They were asked about their sexual performance over the past 4 weeks. Each item provides six response options that are rated from zero to five, where zero represents the poorest function and five, optimal function. Total scores range from zero to thirty [12]. The items are: [A] How would you rate your level ("degree") of sexual desire or interest? [B] How would you rate your level of sexual arousal ("turn on") during sexual activity or intercourse? [C] How often did you become lubricated ("wet") during sexual activity or intercourse? [D] When you had sexual stimulation or intercourse, how often did you reach orgasm? [E] How satisfied have you been with your overall sex life? [F] How often did you experience discomfort or pain during vaginal penetration?

\section{Statistical analysis}

The internal or dimensional structure of the FSFI-6 was explored through confirmatory factorial analysis (CFA), using the maximum likelihood method. To find out whether the group of items had a latent factor, Bartlett's test of sphericity [19], and Kaiser Meyer Olkin measure of sampling adequacy (KMO) [20] were both calculated. These indicators suggest that the factor analysis should be followed, but there is no guarantee of finding a satisfactory dimensional structure. Several goodness of fit indicators was calculated in the CFA: chi square test with degrees of freedom (df) and probability value (p), and the RMSEA coefficient (Root Mean Square Error of Approximation Of the approximation error) with a
90\% confidence interval (CI90\%), the Comparative Fit Index (CFI), the Tucker-Lewis Index (TLI) and SRMS (Standardized Mean Square Residual). These indicators are acceptable if the chi square shows the probability value as being greater than 5\%; for RMSEA, less than 0.06; and CFI and TLI, values greater than 0.89. The internal consistency of the index was estimated using Cronbach's alpha [21] and McDonald's omega [22]. The analysis was performed using STATA [23].

\section{Result}

Factor analysis showed a Bartlett's test chi-square of 5,095.15, $\mathrm{df}=15$ and value $\mathrm{p}<0.001$ and KMO of 0.841 . Following this, one dimension was retained giving an Eigen value of 3.8, which explained $63.3 \%$ of the total variance. In the CFA, the model did not fit perfectly, and had a chi square $=582.04, \mathrm{df}=9, \mathrm{p}<0.001$, RMSEA $=0.211$ (90\%CI 0.197-0.226), CFI =0.888 and TLI=0.813. Commonalities and loadings are presented in the . Several one- or two-dimensional models and different item numbers were tested without adequate goodness of fit. The FSSI- 6 showed high internal consistency with both measurements, Cronbach's alpha was 0.876 (95\%CI 0.867-0.885) and McDonald omega was 0.886.

Table 1: Commonality and loading for each fsfi-6.

\begin{tabular}{|c|c|c|}
\hline Item & Commonality & Loading \\
\hline Sexual desire & 0.479 & 0.692 \\
\hline Sexual arousal & 0.772 & 0.879 \\
\hline Becoming lubricated & 0.416 & 0.645 \\
\hline Reaching orgasm & 0.716 & 0.846 \\
\hline Overall sexual life & 0.738 & 0.859 \\
\hline Discomfort or pain & 0.311 & 0.557 \\
\hline
\end{tabular}

\section{Discussion}

In this study, it was found that a FSFI- 6 showed poor construct validity, despite the high internal consistency among climacteric women from three Caribbean cities in Colombia. In this study, poor construct validity was observed for the FSFI- 6 . This finding differs from that of Santos-Pechorro et al. [24], who using a Portuguese version, found good indicators for construct validity in several coefficients using CFA. However, they reported unsatisfactory RMSEA and omitted chi square and the p value for the chi-square. The construct validity of the scales should be repeated in different population groups $[10,25]$.

In this study, the internal consistency for FSFI-6 was high using two different measures: Cronbach's alpha and McDonald's omega. Previous papers have also reported high internal consistency; for example, Isidori et al. [12] obtained a Cronbach's alpha of 0.79, both Chedraui et al. [13] and Perez et al. [14] obtained 0.91, and Lee et al. [15] found 0.89. However, it is evident that the internal consistency can change by population, meaning that every time the scale is applied to a sample, this must be reported [9]. The FSFI-6 is a recently introduced instrument with few items and easy scoring and interpretation [12]. The performance of short scales is as good as that of extensive instruments that purported a comprehensive 
approach to most of the constructs $[9,10]$. The construct validity should be repeatedly tested by CFA10. The measurement index must be valid and reliable to discover the real prevalence of female sexual dysfunction $[10,26]$.

Possibly, part of the problems of the construct "female sexual dysfunction" derive from the bases of "normality" for female sexual function as they evaluate sexual function comparing it to male sexual response. Also, the construct does not consider that changes in female sexual response through life, do not necessarily represent a sexual dysfunction $[2,27]$. The present study is a contribution to the knowledge of the psychometric performance of the FSFSI in Colombian Caribbean climacteric women, especially considering the calculation of CFA [28], and McDonald omega as a measure of internal consistency, which has been omitted in previous studies $[22,29,30]$. Nevertheless, the study presents the limitation inherent to this type of research, which does not allow generalizations as psychometric performance changes according to populational characteristics [9].

\section{Conclusion}

To conclude, the FSFI- 6 presents a one-dimensional structure with high internal consistency in climacteric women from Colombian Caribbean coast. However, the data's goodness of fit is inadequate. New research is needed to verify the construct validity of the FSFI-6 in other populations.

\section{Conflicts of Interest}

The authors have no potential conflict of interest to disclose

\section{Acknowledgment}

The project was supported by a grant from the University of Cartagena, Colombia (Act of engagement $N^{\circ} 126-2017$ between the Universidad de Cartagena, Colombia and the Grupo de investigación Salud de la Mujer.

\section{References}

1. American Psychiatric Association (2013) In: Diagnostic and Statistical Manual of mental disorder. ( $5^{\text {th }}$ edn), American Psychiatric Association, Washington DC, USA

2. West SL, Vinikoor LC, Zolnoun DA (2004) Systematic review of the literature on female sexual dysfunction prevalence and predictors. Ann Rev Sex Res 15: 40-172.

3. McCool ME, Zuelke A, Theurich MA, Knuettel H, Ricci C, et al. (2016) Prevalence of female sexual dysfunction among premenopausal women A systematic review and meta-analysis of observational studies. Sex Med Rev 4: 197-212

4. Cabral PU, Canário AC, Spyrides MH, Uchôa SA, Eleutério J, et al. (2013) Determinants of sexual dysfunction among middle-aged women. Int J Gynecol Obstet 120: 271-274.

5. Clayton AH, Juarez EMV (2017) Female sexual dysfunction. Psychiatr Clin 40: 267-284

6. Blümel JE, Chedraui P, Baron G, Belzares E, Bencosme A, et al. (2009) Sexual dysfunction in middle-aged women: a multicenter Latin American study using the Female Sexual Function Index. Menopause 16 1139-1148.
7. Sánchez SC, Chedraui P, Pérez LFR, Ortiz Benegas ME, Palacios DFY (2016) Evaluation of sexuality in a Paraguayan mid-aged female urban population using the six-item Female Sexual Function Index. Climacteric 19: $256-60$

8. Wolpe RE, Zomkowski K, Silva FP, Queiroz APA, Sperandio FF (2017) Prevalence of female sexual dysfunction in Brazil: A systematic review. Eur J Obstet Gynecol Reprod Biol 221: 26-32.

9. Keszei AP, Novak M, Streiner DL (2000) Introduction to health measurement scales. J Psychosom Res 68(4): 319-323.

10. Reise SP, Waller NG, Comrey AL (2000) Factor analysis and scale revision. Psychol Assess 12(3): 287-97.

11. Rosen R, Brown C, Heiman J, Leiblum C, Meston R, Shabshig D, et al (2000) The female sexual function index (FSFI): a multidimensional self-report instrument for the assessment of female sexual function. J Sex Mar Ther 26: 191-208.

12. Isidori A, Pozza C, Esposito K, Giugliano D, Morano S, et al. (2010) Development and validation of a 6-item version of the female sexual function index (FSFI) as a diagnostic tool for female sexual dysfunction. J Sex Med 7(3): 1139-1146.

13. Chedraui P, Pérez-López FR, Sánchez H, Aguirree W, Martínez N, et al. (2012) Assessment of sexual function of mid-aged Ecuadorian women with the 6-item Female Sexual Function Index. Maturitas 71(4): 407412.

14. Pérez-López FR, Fernández-Alonso AM, Trabalón-Pastor M, Vara C, Chedraui P (2012) Assessment of sexual function and related factors in mid-aged sexually active Spanish women with the six-item female sex function index. Menopause 19(1): 1224-30.

15. Lee Y, Lim MC, Joo J, Park K, Lee S, et al. (2014) Development and validation of the Korean version of the Female Sexual Function Index-6 (FSFI-6K). Yonsei Med J 55(5): 1442-1446.

16. Shairi MR, Moghadam A, Ali M, Rahmati N (2014) The study of the psychometric properties of the 6-item version of the female sexual function index (FSFI-6) amongst Iranian women. J Urm Nurs Midwif Fac 12: 532-543.

17. Chedraui P, Pérez-López FR (2015) Assessing sexual problems in women at midlife using the short version of the female sexual function index. Maturitas 82(3): 299-303.

18. Giraldi A, Rellini A, Pfaus JG, Bitzer J, Laan E, et al. (2011) Questionnaires for assessment of female sexual dysfunction: a review and proposal for a standardized screener. J Sex Med 8(10): 2681-2706.

19. Bartlett MS (1950) Test of significance in factor analysis. Br J Psychol $3(2): 77-85$

20. Kaiser HF (1974) An index of factorial simplicity. Psychometrika 34(1): 31-36.

21. Cronbach J (1951) Coefficient alpha and the internal structure of test. Psychometrika 16(3): 297-334.

22. McDonald RP (1970) Theoretical foundations of principal factor analysis and alpha factor analysis. Br J Math Stat Psychol 23(1): 1-21.

23. (2013) STATA 13.0. College Station: STATA.

24. Santos PP, Monteiro PP, Monteiro PN, Poiares C, Neves JS, et al. (2017) Validation of the portuguese version of the female sexual function index-6. Rev Int Androl 15: 8-14.

25. Streiner DL (1994) Figuring out factors: the use and misuse of factor analysis. Can J Psychiatry 39: 135-140.

26. Hayes RD, Dennerstein L, Bennett CM, Fairley CK (2008) What is the "true" prevalence of female sexual dysfunctions and does the way we assess these conditions have an impact? J Sex Med 5(4): 777-787. 
27. Miccio Fonseca LC (2015) Response to ross's commentary: problems with the sexual disorders sections of dsm-5. J Child Sex Abuse 24(4) 202-209.

28. Jackson DL, Gillaspy Jr JA, Purc SR (2009) Reporting practices in confirmatory factor analysis: An overview and some recommendations. Psychol Method 14(1): 6-23.
29. Hogan TP, Benjamin A, Brezinski KL (2000) Reliability methods: a note on the frequency of use of various types. Educ Psychol Meas 60(4): 523531.

30. Rogers WM, Schmiti N, Mullins ME (2002) Correction for unreliability of multifactor measures: Comparison of alpha and parallel forms approaches. Org Res Method 5(2): 184-199.
Creative Commons Attribution 4.0 International License

For possible submissions Click Here

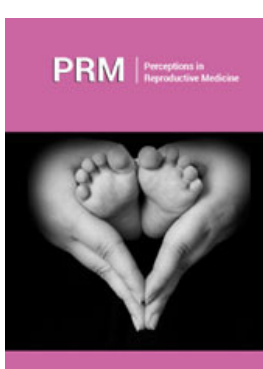

Perceptions in Reproductive Medicine

\section{Benefits of Publishing with us}

- High-level peer review and editorial services

- Freely accessible online immediately upon publication

- Authors retain the copyright to their work

- Licensing it under a Creative Commons license

- Visibility through different online platforms 